\title{
A Model For Value Chain INTEgRation in a VerTiCally INTEGRATED DESIGN AND MANUFACTURING FIRM
}

\author{
Arunkumar Subramanian, Dr. Hongyi Sun \\ Department of Systems Engineering and Engineering Management, City University of Hong Kong, Hong Kong
}

\begin{abstract}
Value chain concepts usually remained descriptive in construct acting only as a heuristic tool, yet widely benefiting the global commodity chain analysis activities for few decades already. This paper observes that value chain concept can be made even more beneficial with integrated value chain model when applied for firm level activities. Using the concepts of value chain \& perceived customer value, a system of processes called value packet has been developed to integrate the internal activities of a firm. Value packet computes the customer value and ensures a predetermined amount of value is being added to product throughout its own value chain. Primary \& strategic value model calibrates the firm's primary value chain to respond optimally according to different product development needs to create desired customer value making the entire value chain dynamic. This paper briefs a conceptual model of an integrated value chain especially suitable for a vertically integrated design and manufacturing firm.
\end{abstract}

Keyword: Integrated value chain; Primary value chain; Perceived customer value; Value packet
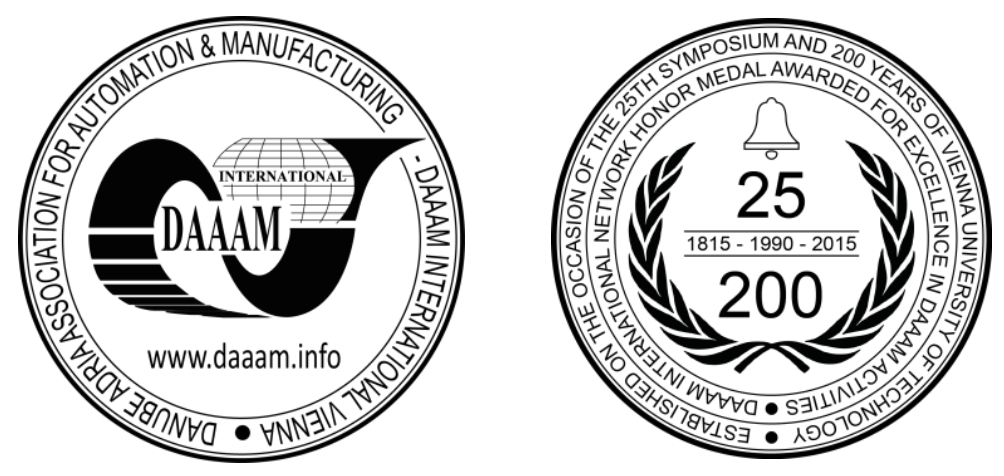

This Publication has to be referred as: Subramanian, A[runkumar] \& Sun, H[ongyi] (2016). A Model for Value Chain Integration in a Vertically Integrated Design and Manufacturing Firm, Proceedings of the 26th DAAAM International Symposium, pp.0327-0335, B. Katalinic (Ed.), Published by DAAAM International, ISBN 978-3-90273407-5, ISSN 1726-9679, Vienna, Austria

DOI:10.2507/26th.daaam.proceedings.044 


\section{Introduction}

Value chain concept in some way or other, are intended to express the value addition process while creating a product or solution for a customers. "Value addition is a process by which technology is combined with material and labour inputs and then the processed inputs are assembled, marketed and distributed" [1]. It was also pointed out that a single firm may consist of one link in the process or it may be extensively vertically integrated [1]. Value addition process is better mapped in a value chain. A vertically integrated firm can effectively be a value chain of its own. Reference [2] developed value chain concept to analyse specific activities through which firms may create value by breaking down their activities into primary activities and support activities [2]. The scope of value chain was further diversified with the development of global commodity chain by Gereffi in 1990s [3] which could establish input-output structure, territorial structure, and institutional frame work and governance structure [4]. Reference [5] distinguished the value chain concepts according to organizational and spatial scale [5].

In spite of their varied scope and scale, the characteristics of value chain remained highly descriptive in construct, advisory to conduct analysis, recommendation for improvements. The nature of value chain remained static and thus any further alterations required additional set of analysis and improvement plans. Moreover, the concept as whole did not provide a mechanism to optimise the value addition by different activities and quantify the customer's perceived value. In order to fill this gap, the value chain has to be made a system of process that continuously adjust itself to the varying needs of value creation process without altering the physical infrastructure while managing the value addition process to increase different customer's value perception.

The difference between the value of output of a product and the value of the intermediate input used in the product activities by a firm represents the value-addition in financial terms [6]. However, the focus of value addition has shifted towards satisfying the perceived customer value. The ability for a firm to provide superior value to their customer has been an important constituent of relationship marketing and a successful strategy [7]. Yet, the ability to codify the perceived customer value and translate them into deliverable value proposition was not well established for many industrial firms. Integrating a firm's value chain can streamline a firm's processes and improve customer value through greater connectivity between both business processes and key operational systems [8]. This paper discuss a systematic methodology to make an enterprise's value chain into an integrated value chain so that every value addition activity is quantified, optimized and aligned with the firm's business strategy. A vertically integrated design and manufacturing firm provides enough scope for value chain integration process.

\section{The integrated value chain}

Value system (chain) integration can be defined as the process by which multiple enterprises within a shared market segment collaboratively plan, implement and manage the flow of goods, services and information along the value system (chain) in a way that increases customer-perceived value and optimizes the efficiency of the chain [8]. The above definition states that there should be a process to plan, implement and manage the flow of goods, services and information along the value chain to integrate it. But, it does not specify what mechanism exactly does the integration upon a value chain. At this point, it is important to understand what a value chain is and what process can better integrate it? One comprehensive definition of value chain from literature states that a value chain describes the full range of activities that firms and workers do to bring a product from its conception to its end use and beyond [4]. And the activities includes design, production, marketing, distribution and support to the final consumer [4]. Thus far definition only identifies the path along which different value addition activities are taking place, exhibiting the links and relationships between them. Due to the complexity involved, the methodologies are heuristic [9] and doesn't essentially display the dynamism of a value chain.

This paper defines an "integrated value chain" as a responsive system that creates a product or solution for the customer requirement using a system of process called value packet which is capable of quantifying, measuring and managing the value of each activity across the value chain. The Integrated value chain is capable of calibrating its response to the value packet created for every product or solution development needs. Where, the value chain is defined as a "plan of an enterprise" indicating the flow of material, service and information through different divisions of primary activities which would enable the addition of a predetermined value to product or service with the supports of many other secondary activity divisions. While, the value packet is a predetermined system of process that is created for every individual product or solution according to the perceived customer value for every project. This value packet will act as a vehicle to move the product or solution across the value chain.

Primary value chain of an enterprise lays the foundation for integrated value chain whereas the support activities would align and respond to the demands of a primary value chain. Different primary activities of an enterprise are arranged in the same sequence by which the values are added on the product creation process. Figure 1 shows the schematics of a primary value chain of an enterprise. Business division of an enterprise will be the starting point of an integrated value chain while other activity divisions follows. Engineering division adds technology value with design and development activity. Manufacturing divisions adds the quality value while producing the physical product. Distribution manages the inventories and makes sure that the product and solutions are delivered to the customer, ensuring a delivery value. Internal component and supply chain divisions ensures that materials are supplied appropriately. Though the value addition by internal components and supply chain divisions are unaccounted for value 
packet, their presence in the internal value chain is justified as they are part of material flow process. Raw materials and components as supplier's direct material category is procured with the help of supply chain division. The Internal components division partially consumes the supplier's direct materials and convert them into internal components. The internal components and the supplier's direct materials are used by the manufacturing division to produce the required product or solution. The distribution division physically transport the produced solution or product to their respective customer. So, the material flow is unidirectional starting from supplier until the customer.

Every activity division in the primary value chain have to tender certain service to their preceding activity divisions. For example, the product development service provided by engineering division is considered as service tendered to business division. As an entire system, every service is to be considered as service tendered to all the preceding divisions. So, service flow in unidirectional in reverse direction to value addition process flow. Information flow is multi directional as there will service request and acknowledgements between activity divisions. The information flows in the direction as the value packet command. Strength of the value chain integration depends on how well the information is managed. Information flow includes plan, design, orders and complaints.

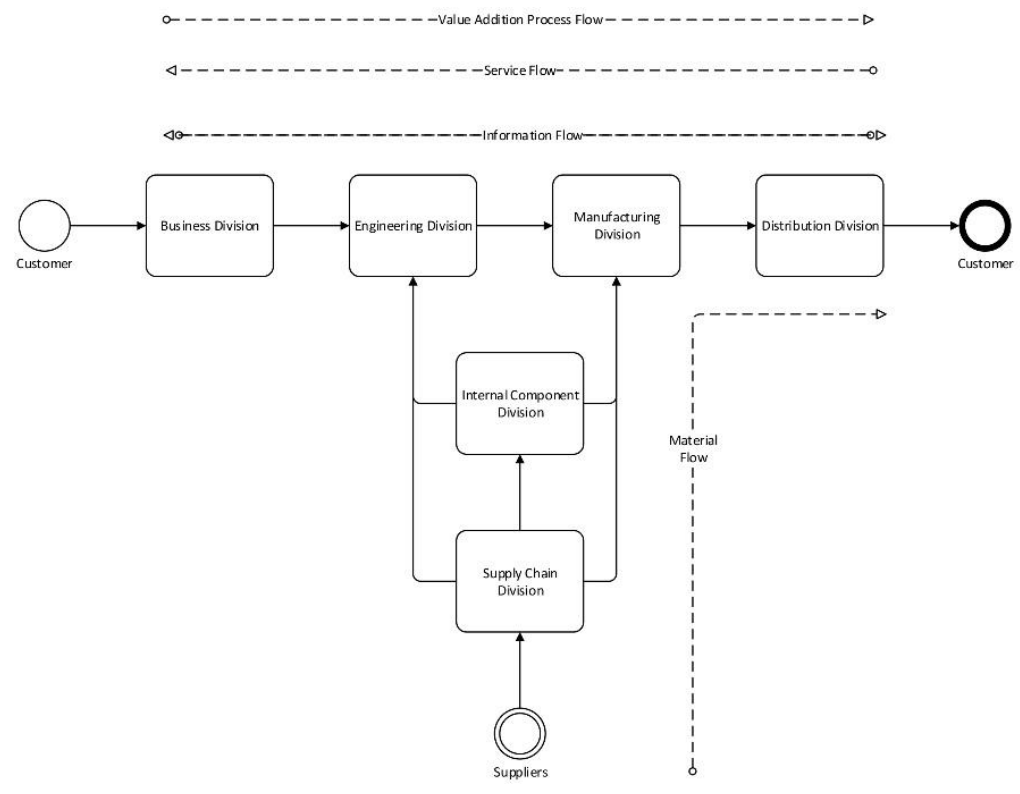

Fig. 1. Primary value chain of a vertically integrated design \& manufacturing firm

\section{The perceived customer value}

Value is defined in the pricing literature as the trade-off between customers' perceptions of benefits received and sacrifices incurred [7]. Many authors noted that the role of price is complex and customers do not buy solely on the basis of low price. Reference [9] quoted: "Customer value is a customer's perceived preference for and evaluation of those product attributes, attribute performances, and consequences arising from use that facilitate (or block) achieving the customer's goals and purposes in use situations". Although the multiple contexts, tasks and criteria in the above definition reflect the richness and complexity of the concept, they hamper its interpretation into a measurable operational definition [10]. The difficulty in defining the value emerges from subjectivity of value in regards to different customers in different situation. This paper, after reviewing the scholar's viewpoint in defining customer value takes a new approach to translate the perceived customer value to enterprise's deliverable value.

Through this an enterprise can concentrate on what it can offer to the customer in definite agreement of value to its customer instead of investigating customer's perception that could be difficult to comprehend at times. When an enterprise is clear about what it can offer, it could be relatively easy to define certain metric of value and same could be made clear to the customer. As [11] suggested, the access to information on how a value is built for a product that is being bought by a customer can put them in better place to determine the value. It is possible to bring the customer to such an agreement in early phase of product development, and in case of miss- match with co-perception of value, the enterprise also can filter with what customer they can look forward to work with. This can reduce the ambiguity in handling the value transaction between an enterprise and a customer. The content of deliverable value as proposed by this paper, constitutes a set of primary value that translates directly the customer's product or solution related attributes and a set of strategic values that deals with tactical businesses and customer relation aspects. Values of technology, quality, delivery, responsiveness and cost abbreviated as "TQDRC" are proposed as a matrix of deliverable value for a vertically integrated globalised design and manufacturing enterprise operating in business to business environment. The benefits perceived by the customers can directly be interpreted as product related attributes whereas the perceptions related to scarification made my customer has to be managed strategically. 


\section{The primary value model}

The set of primary values may best constitute of technology value, quality value and delivery value. Primary values are the core competencies of an enterprise that look after the customers technical requirements directly. Since technology, quality and delivery are coming from different divisions of activity, any variation in the combination of these value will need different set of value chain to operate with maximum efficiency and effectiveness. The various combination of primary values forms the primary value model that actually make the enterprise value chain a dynamic system. If technology, quality and delivery values are represented as T, Q and D respectively, then we have a series of combinations like TQD, TQ, QD, TD, T, Q and D. Each of this model represent a unique primary value chain characteristics. Figure 2 is a representative primary value chains for QD model as an example.

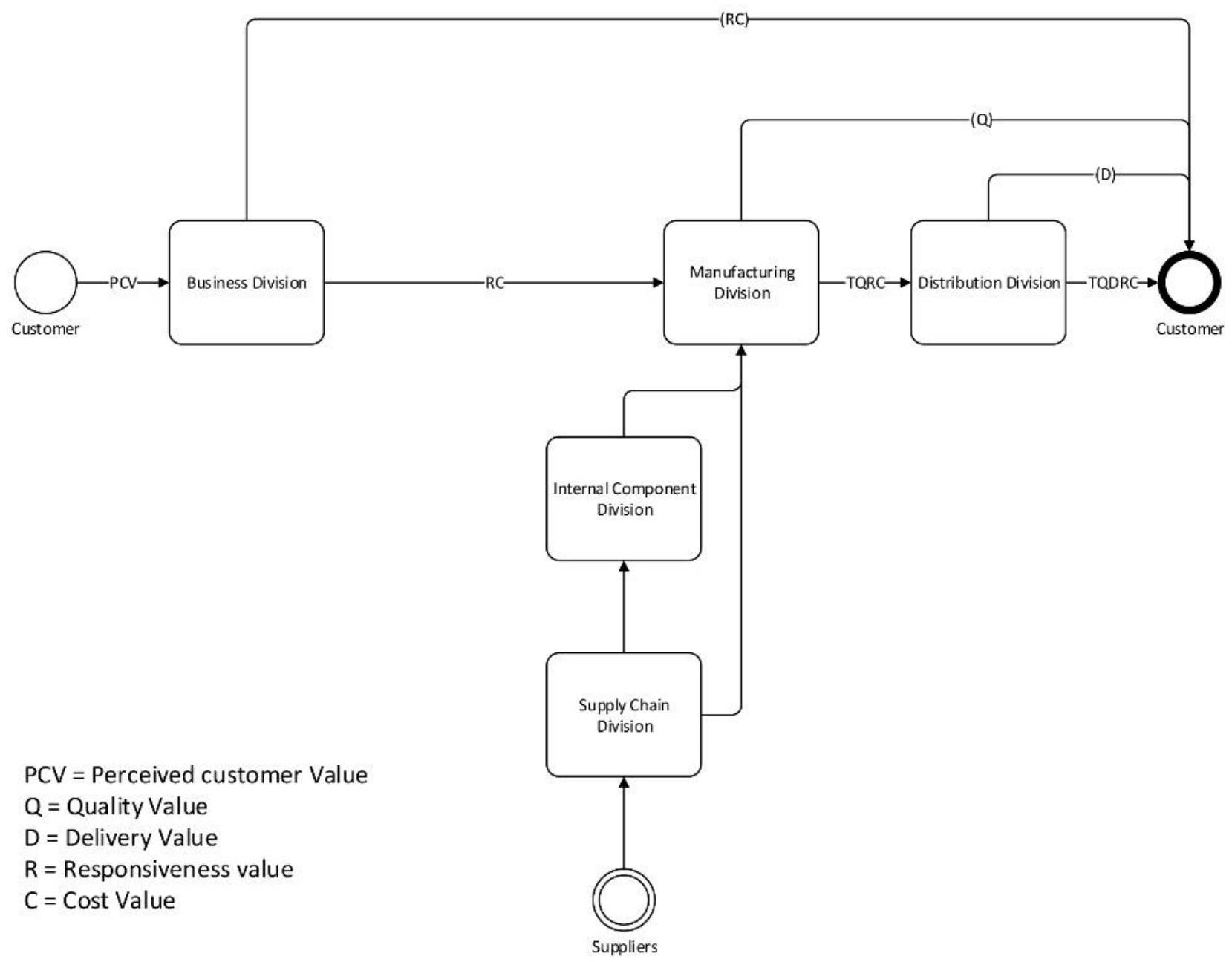

Fig. 2. Primary value chain for 'QD' primary value model

\section{The primary value metrics}

\subsection{Technology value metrics $(T)$}

The function of engineering division in the value chain of an enterprise is to design and develop new product or solution. Technology of the product or solution developed by an enterprise may become integral part or even closely interact with other technologies found in the final product or solution of the customer. An enterprise invest time, effort and resources to develop technology for providing product and solution to its customer. When such a technology is unique or special, it would add tremendous value to the customer's final product. For an engineering division to quantify its value, the structure and way it function has to be clearly defined and understood. The structure should be explained in the internal value chain of the engineering division. Technology competency, technology complexity, development resources and development time constitutes the variables involved in determining technology value metrics. Figure 3 is a model that helps to consign certain metric to the technology value. 


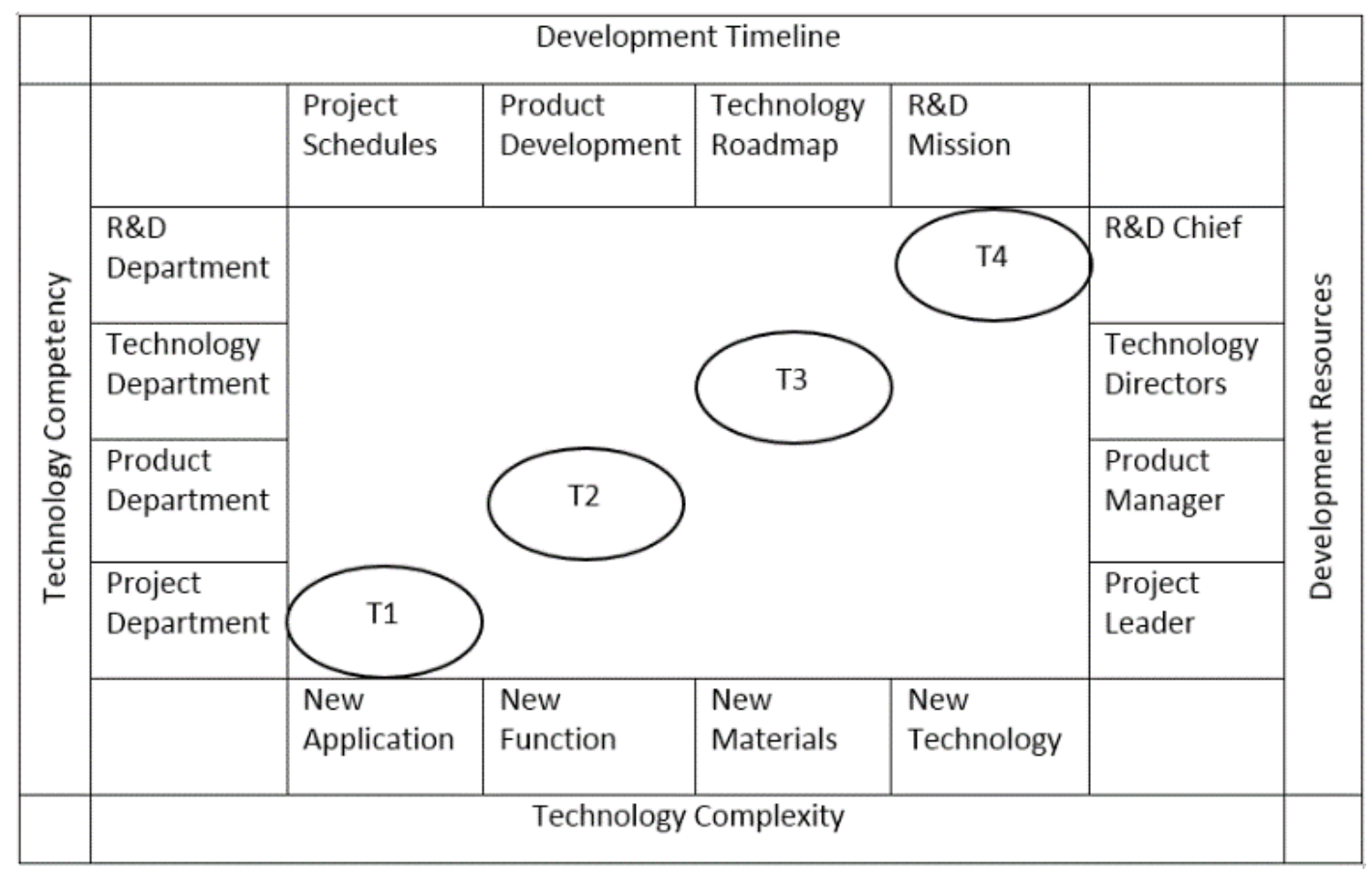

Fig. 3. Technology value metric model

\subsection{Quality value metrics $(Q)$}

Quality is a perceptual, conditional, and somewhat subjective attribute and may be understood differently by different people [12]. Customers may focus on the specification quality of a product/solution, or how it compares to competitors in the marketplace. Producers might measure the conformance quality, or degree to which the product/service was produced correctly. The metric of quality value is somewhat a measure of effort deployed by a producer to uphold the product attribution conformance in relation to the risk profile and warranting the same over the specified life time. Metric model is developed keeping risk assessment matrix, level of quality control and quality assurance as the fundamental input system as shown in the Figure 4.

a

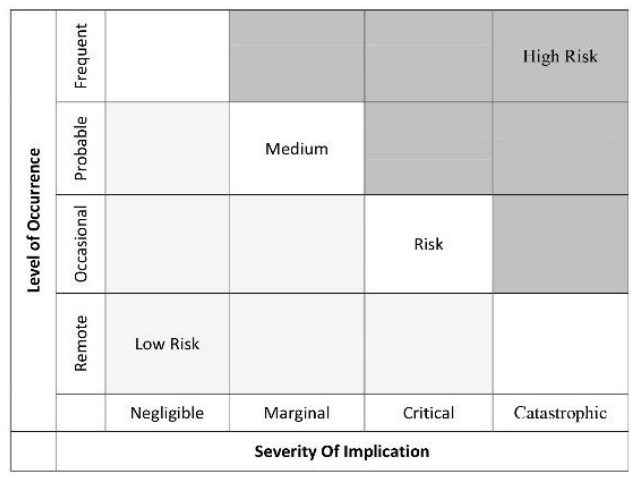

b

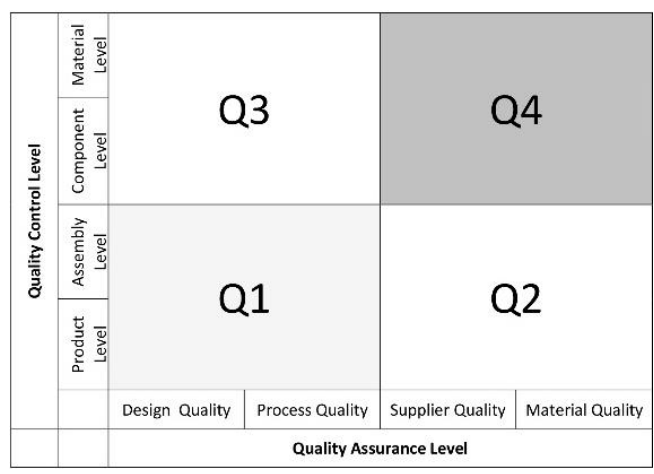

Fig. 4. (a) Risk profile matrix (b) Quality value metric model

\subsection{Delivery value metrics $(D)$}

Highly globalized market environments now offer significant opportunities for multinational companies to move their manufacturing and distribution activities throughout the world. Within this context, researchers argue that the global manufacturing strategies alone may not be effective if not supported by successful logistics/supply-chain management strategies [13]. While basic logistics decisions mainly deal with physical movement of the products, [14] emphasized adoption of a more comprehensive framework for logistics strategy that includes cost management, a focus on simplifying transactions faced by customers, and information exchange throughout the channel. In other words, part of the value that a company creates for its customer is its ability to deliver the right product in the right amount at the right place at the right time for the right customer in the right condition at the right price [15]. The variables involved in transferring a product or solution from supplier to customer are the major concerns. The variable involves transportation cost, inventory of product at supplier as well as customer location, the distance of logistics, the locations involved, the 
time of transportation, right timing at which the product is being delivered, the frequency at which the products are transported, the quantity of product transported each time, the condition of products being transported, the mode of transportations, regulatory constraints involved in transportation, etc. Many time it is possible that these variable are interdependent. If one variable is solved other would get worse or solved even without any effort. This paper instead of looking after the interdependency among the variable, has chosen four most important variables that bothers most of the customers to construct the value metrics as shown in the Figure 5.

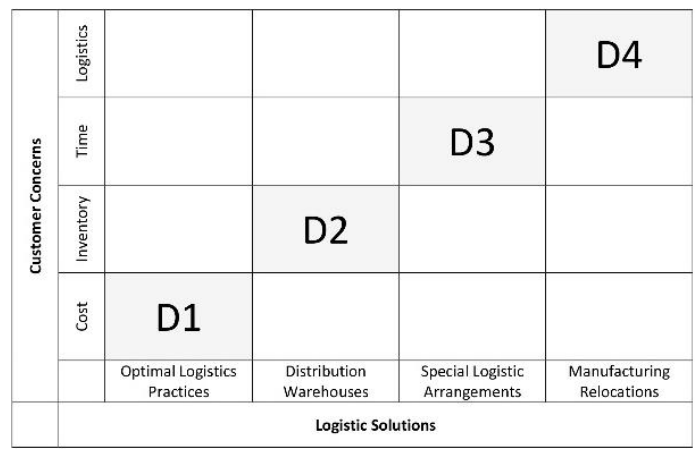

Fig. 5. Delivery metric model

\section{The strategic value model}

An enterprise have to see how the value created internally transacted to its global customers in a strategic way. The learning required to effectively develop the capability to engage in certain value chain activities may be difficult, time-consuming, and effectively impossible for some enterprises to acquire, regardless of frequency or scale economies [16]. Though the customers' requirements are looked after by primary value model, strategic value model is developed to handle the circumstance underlying a business transaction. Strategic values constitutes the cost and responsiveness value that business division decide to offer to a customer depending on the value that it receives back from a business transaction. The strategic values deploys a balance pointer for core competency and complementary competencies. Such appropriation of value dispersion are complex decision and this paper proposes a mechanism to systematically guide a business division to take such decisions. "If a theory of value chain governance is to be useful to policymakers, it should be parsimonious. It has to simplify and abstract from an extremely heterogeneous body of evidence, identifying the variables that play a large role in determining patterns of value chain governance while holding others at bay, at least initially" [17]. Reference [17] proposed a new typology of value-chain governance outlining some empirical reference points taken from many studies particular based on the characteristics of global value chains. This typology seek to explain industry organization - from transactions costs to global commodity chains to organizational theory based on the market-based relationships among enterprises and within vertically integrated enterprises and those concepts of governance became the foundation for the proposed strategic value model in this paper. The model overlays a plan to manage the expectation of a project and its customer at once within an enterprise's value chain. The model is to be deployed after understanding the worthiness of business, complexity involved in the business transaction and competency required to enable a business transaction for a particular project. However, the concepts of business worthiness, complexity and competency analysis are not explicitly covered in this paper in order keep the core subject of the topic intact. Figure 6 is a strategic value model, deploying value chain governance pattern. The model propose a new analysis tactics to look at the project and the customer of business division in a singular format and grouped format. By doing so certain pattern of characteristics and their respective indescribable demands are unearthed. Strategic success of an enterprise depends on how well such distinctiveness of project and the customers are dealt with. Reference [17] provided an excellent insight to comprehend this new perspective with their concepts of global value chain governance and patterns.

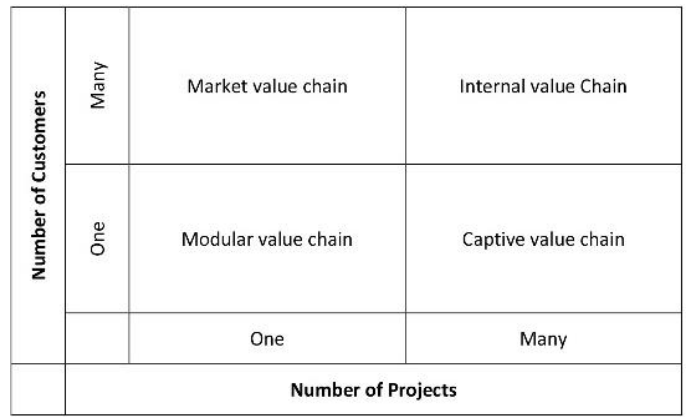

Fig. 6. Strategic value model deploying value chain governance pattern 
Market relations work well for standard products because they are easily described and valued [17]. "When transactions are easily codified, product specifications are relatively simple, and suppliers have the capability to make the products in question with little input from buyers, asset specificity will fail to accumulate and market governance can be expected [17]. Coordination problems are reduced not only because their ease of description makes contracts simple to write, but also because standard products can be produced for stock and supplied as needed. In the context of value chain, if there is one project that can be sold to many customer, that project signifies that the technology being used is not unique. A series of product generated under a generic technology could be considered to be quite commoditized within the enterprise. That means, the technology and know-how to produce such product are common within an enterprise. By grouping them together under market value chain, standardization in product technology is achieved. In market exchange buyers respond to specifications and prices set by sellers.

The more customized the product or solution, the more likely it is to involve transaction-specific investments [17]. This raises the risk of opportunism, which either rules out outsourcing altogether, or makes it more costly because safeguards have to be put in place. With respect to an enterprise level value chain, modular value chain simply means that there is one project that is specific to only one customer, signifying a greater level of customization with a higher level of customer intimacy. Normally an enterprise could agree to do one project specific to one customer only when the project worth is significant as is governed with modular value chain patterns.

An enterprise can run projects without any customer linked to it. The aim for this type of project is to develop new technology or product platform for which new customer will be identified later on. Enterprise identifies new technology or product development needs through its market research analysis. The concepts of product and technology that are generic to industry segment are strategic projects validated within an enterprise first. Such activities requires less contribution from internal value chain but are strategically significant. This projects are governed with internal value chain characteristics.

When the complexity of product specifications and ability of an enterprise to codify the customer requirement are high, and at the same time the governance of relationship between customer and enterprise are well placed, then value chain governance will tend toward the captive type. This is because proven supplier competence in the face of complex products and specifications encourages the build-up of transactional dependence as customer seek to lock-in suppliers in order to receive compliments based on earlier transaction specific investments. This simple means that one customer will be dealing with multiple projects with an enterprise. Here a customer become captive and thus an enterprise values the needs of the customer more than the systematic value creation with in a project.

\section{The strategic value metrics}

\subsection{Cost value metrics $(C)$}

Giving away a value of cost for something is highly circumstantial and yet more strategic. There could be many costing model that best fit the transactional circumstances. The cost value doesn't simply mean being cheap and in many circumstance may not abide by the cost of product theory. The cost-of-production theory states that the price of an object or condition is determined by the sum of the cost of the resources that went into making it. The cost can comprise any of the factors of production (including labour, capital, or land) and taxation [18].

\begin{tabular}{|c|c|c|c|c|c|c|}
\hline & \multicolumn{5}{|c|}{ Enterprise Business Attributions } & \multirow{6}{*}{ 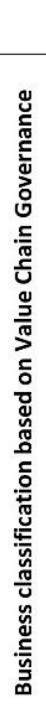 } \\
\hline \multirow{5}{*}{ 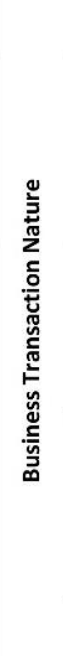 } & & Competitiveness & Core Competency & Customer Intimacy & & \\
\hline & 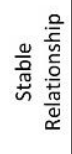 & & & $\begin{array}{c}\text { Cost value } \\
\text { Type } 3\end{array}$ & 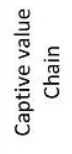 & \\
\hline & 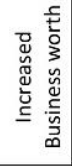 & & $\begin{array}{c}\text { Cost value } \\
\text { Type } 2\end{array}$ & & 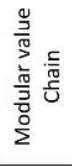 & \\
\hline & 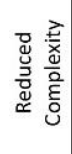 & $\begin{array}{c}\text { Cost value } \\
\text { Type } 1\end{array}$ & & & 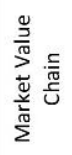 & \\
\hline & & Lower Cost & Higher Differentiation & Stable Responsiveness & & \\
\hline & & & ctations from the Cus & mer & & \\
\hline
\end{tabular}

Fig. 7. Cost value metric model 
For the nature of enterprise defined in this paper, cost value is different for different customers in different value chain governance. Cost value is different for different project with different primary value models yet cost value metric model is not a pricing tool. However, the cost model for internal value chain is not included as the focus of such value chain is realizing the product at first. Figure 7 shows the Model where Type 1 cost value indicates less complex, price sensitive, market governance leveraging market competitiveness. Type 2 cost value model leverages on core competency of supplier looking for differentiated product often with huge business value. Whereas, Type 3 value model for a captivated customer who enjoys long term relationship with stable response model.

\subsection{Response value metrics $(R)$}

Trust is a rare commodity and trust in an enterprise is formed as a result of judgments people make about its behavior over time [19]. Only one in twenty customers trusts the enterprises that give him/her services, while only one in forty customers believe that the enterprise trusts him/her [20]. The inability to create trust has an "intangible" as well as a tangible price that is particularly high [21]. Responsiveness is a strategy to direct an enterprise to respond well towards its customers business and emotional needs. An enterprises aims in making a customer successful beyond making them happy. Every customer have different level of needs and deserve a specific attentiveness. A small effort in helping them manage their business needs which they are lacking for themselves would make them successful and there is a possibility to retain them for longer business partnership. A model where one can assume, sensitivity of response for captivated customers are high while it is relatively low and medium for market and modular value chain governance can be deployed with metrics ranging from R1 to R4. The model is not included in this paper.

\section{Value packet and integration process}

Value packet is a system of processes that is used to integrate a firm's value chain. After converting the customer value into deliverable value matrix constituting primary and strategic value metrics, a value packet is defined. A combination of different value metric say T4, Q3, D1, C2 and R1 for example would form a value packet for a given project. That packet gets processed across the primary value chain and delivered to customer anticipating their value. Primary values are quantified using their respective metric models, after determining the primary value chain structure resulting from primary value model. Metric for technology, quality and delivery are stipulated by engineering, manufacturing and distribution divisions and directed to business division to compile the value packet. Strategic value model is used by the business division - a foremost activity division in a primary value chain to comprehend and launch the matured value packet. Strategic value metric are assessed and integrated with primary value metric to form a complete value packet. The value packet defines the information, material, and service flow direction and also determines the resource and response required at each activity division to process and deliver the value attached to it. Value packet uses enterprise infrastructure to navigate along the primary value chain as established by the primary value model and ensure required value is added upon by different activity division.

\section{Features of integrated value chain}

Integrated value chain is constructed based on the enterprise's primary value chain and is designed for an enterprise that could operate in a collection of similar industrial segment. Business divisions would strategically divide its business activities based on four classified value chain patterns called market, modular, internal and captive value chains. A project under market value chain aims standardization of product and meeting the expectations of commoditized market segments. Modular value chain is aiming to meet the customized needs of a customer. A project developed under internal value chain aims to create new product platforms to drive enterprise's technological leadership in the industry. Captivated value chain represent the customers of priority who offers more than one project to the enterprise. The product platforms and technology platforms are managed by engineering division that contributes technology value. The manufacturing division uses a collection of components and raw materials to produce a solution or product by adding quality value. Components and raw materials are purchased by supply chain division while some components are produced internally indicating vertical integration strengths. Distribution division manages the physical transfer of products from enterprise to customers and materials from the suppliers to activity divisions of enterprise adding delivery value.

The values of every single project is captured in value packet and processed for value addition by moving it all across the enterprise's primary value chain thus making an integrated value chain. Primary value model determines the construct of the primary value chain making it a dynamic system for every value packet. Integrated value chain manages the physical build of a product from every single supplier to every single customer across the primary value chain all through the enterprise. Integrated value establishes seamless connection between the activity divisions of enterprise even if they are physically located in different geographical regions throughout the world with standardized operation. Integrated value chain virtually connects all the activity divisions so that the expected value additions from each division are communicated in advance and thus the entire value chain calibrate its responsiveness for a particular project. 


\section{Conclusion}

The result of this paper is development of a conceptual model for integrating a value chain. The model is developed based on the literature analysis. Short coming of the generic value chain concepts are highlighted. The gaps are systematically filled up to construct an integrated value chain. Perceived customer value - an important measure in contemporary business transaction has been invoked into the value chain construct. Metric systems to quantify the customer value has been involved. Primary value model has been developed to covert the static nature of generic value chain into a dynamic one. Strategic value has been used to manage the customer and their product needs systematically. Ultimately, a system of process called value packet has been developed to integrate an actual value chain. With value packet as a system of process makes a value chain highly dynamic and integrated, indicating a better operational efficiency. The current model has limitation as the specific activity based tools to generate the value packet has not been presented here and also the model has not been tested in real case situation. However, different steps involved in constructing an integrated value chain is covered by this paper. As future work, the author will apply the model into a vertically integrated global design and manufacturing firm to see how the integration process is delivering the customer value through its dynamic primary value.

\section{References}

[1] B. Kogut, "Designing Global Strategies: Comparative and Competitive Value-Added Chains," MIT Sloan, Management Review, July 1985. [Online]. Available: http://sloanreview.mit.edu/article/designing-globalstrategies-comparative-and-competitive-valueadded-chains/. [Accessed 21 September 2015].

[2] M. Porter, Competitive Advantage: Creating and Sustaining Superior Performance, NewYork: The Free Press, 1985.

[3] Gary Gereffi, "A Commodity Chains Framework for Analyzing Global Industries," Duke University, Durham, USA, 1999.

[4] Kaplinsky R. \& Morris M., "A HANDBOOK FOR VALUE CHAIN," 2000.

[5] T. J. Sturgeon, "How Do We Define Value Chains and Production Networks," IDS Bulletin, vol. 32, no. 3, 2001.

[6] F. Tallec and L. Bockel, "Commodity Chain Analysis: Financial Analysis," Food and Agriculture Organization of the United Nations, FAO, Rome, Italy, 2005.

[7] Jyoti Sikka Kainth and Harsh V Verma, "Consumer Perceived Value: Construct Apprehension and its Evolution," Journal of Advanced Social Research, pp. 20-57, 2011.

[8] Papazoglou Michael P. Piet Ribbers b. and Aphrodite Tsalgatidou, "Integrated value chains and their implications from a business and technology standpoint," Decision Support Systems, pp. 323-342, 2000.

[9] Tamás Bányai, Péter Veres and Béla Illés, "Heuristic Supply Chain Optimization of Networked Maintenance Company," in 25th DAAAM International Symposium on Intelligent Manufacturing and Automation, Procedia Engineering 100 ( 2015 ) 46 - 55, DAAAM , 2104.

[10] R. B. Woodruff, "Customer Value: The Next Source for Competitive Advantage," Journal Of The Academy Of Marketing Science, vol. 25, no. 2, pp. 139-153, 1997.

[11] Parasuraman. A, "Reflections on Gaining Competitive Advanatge Through Customer Value," The Journal Of The Acedamy Of Marketing Science, pp. 154-161, 1997.

[12] Monroe, Pricing: Making Profitable Decisions, New York: McGraw-Hills, 1990.

[13] "Quality (business)," Wikipeadia, 2007. [Online]. Available: https://en.wikipedia.org/wiki/Quality_(business). [Accessed september 2015].

[14] J. E. Spillan, M. A. MvGinnis, A. kara and L. G. Yi, "A comparison of the effect of logistic strategy and logistics integration on firm competitiveness in the USA and China," The International Journal of Logistics Management, vol. 24, no. 2, pp. 153-179, 2013.

[15] D. J. Bowersox and P. J. Daugherty, "Emerging Patterns Of Logistical Organization," Journal of Business Logistics, vol. 8, no. 1, pp. 46-60, 1987.

[16] R. Shapiro and J. Heskett, Logistics Strategy: Cases and Concepts, St Paul, MN,: West Publishing Co.,, 1985.

[17] C. Prahalad and G. Hamel, "The Core Competence of the Corporation," Harvard Business Review, vol. 68, no. 3, pp. 79-91, 1990.

[18] Gereffi, John.H and Timothy, "The governance of global value chains," Review of International Political Economy, pp. 78-104, 2005.

[19] "Cost-of-production theory of value," August 2015. [Online]. Available: https://en.wikipedia.org/wiki/Cost-ofproduction_theory_of_value.

[20] J. Barlow and P. Stewart, Branded customer service: The new competitive edge, San Francisco: Berrett-Koehler, 2004.

[21] M. Edwardson and W. and Croker, "Sectorial patterns of technological change in services," Economic Innovation and New Technology, pp. 183-221, 2003.

[22] H. Deeneve K. M. and Cooper, "The happy personality a Meta analysis of 137 personality traits \& subjective well being," Psychological Bulletin, no. 124, pp. 197-229, 1998. 